\title{
Product DeVelopment Using an INTELLIGENT SUPPORTING SYSTEM
}

\author{
BUCHMEISTER, B. \& PALCIC, I.
}

Abstract: Improvement of product development process is crucial for all competitive companies. One of the possible steps is the implementation of the supporting system based on neural networks. Development of the product lasts from the first idea about the product till the end of production. In that time a lot of activities take place in order to achieve the success on the market. Too much resources applied in the development phase mean high product's price. If there is too less resources assigned, it could happen the product is qualitatively not sufficient and therefore market rejects it. Optimum development requires minimal resources necessary with preserving quality of the end product. In this chapter we suggest a method for helping the appliance developers, which is based on existing knowledge and foresees potential solutions. The data were collected from various beverage appliances. With neural networks the acquired data were set as a base for creating supporting neural networks. The system was tested with the data that were previously not included into learning patterns. Results show that the method is suitable for new appliance development. System itself predicted expected solutions well enough to confirm usability for development purposes.

Key words: Product development, intelligent system, neural network, support
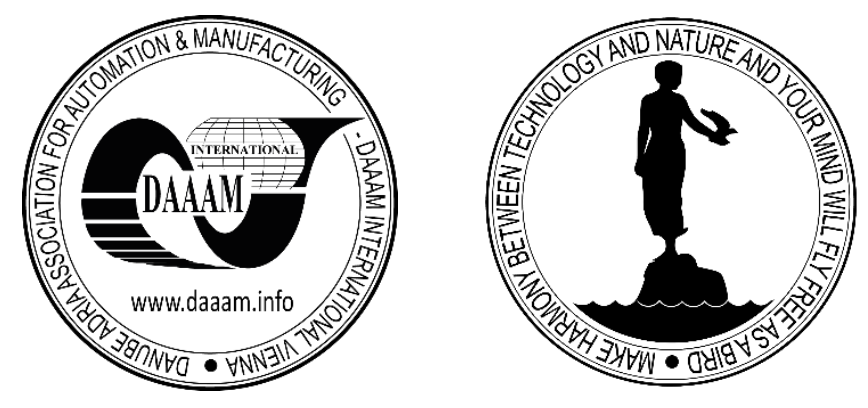

Authors' data: Full Prof. Dr. Buchmeister, B[orut]; Assoc. Prof. Dr. Palcic, I[ztok], University of Maribor, Faculty of Mechanical Engineering, Production Engineering Institute, Smetanova 17, SI - 2000 Maribor, Slovenia, borut.buchmeister@um.si, iztok.palcic@um.si

This Publication has to be referred as: Buchmeister, B[orut] \& Palcic, I[ztok] (2017). Product Development Using an Intelligent Supporting System, Chapter 04 in DAAAM International Scientific Book 2017, pp.043-054, B. Katalinic (Ed.), Published by DAAAM International, ISBN 978-3-902734-12-9, ISSN 1726-9687, Vienna, Austria

DOI: $10.2507 /$ daaam.scibook.2017.04 


\section{Introduction}

Companies around the world face fiercer competition every year. Borders of the market had erased in the last couple of years in a manner that virtually everyone in the world could compete in a global market. This means greater choice for the customer. On the other hand it means that a company has to push even harder for the market share. Since the companies work on the global market this means that they compete with multinationals as well as new companies formed just a while ago.

Because of ever stricter market situation which is delegated by the competition as well as more demanding customers, the companies itself need to examine even more in detail how to gain competitive edge. For the company which main business is development of the end products one of the focuses (if not the main focus) is set on development. Development is a broad term which contains many different areas. It contains different motivations, goals and methods for achieving them (Brglez \& Dolsak, 2016; Koren \& Palcic, 2015). The thing that matters the most is the end product. So we can say that developing the appliances is goal oriented project or activity for achieving that goal with minimum required effort.

During the last couple of years development changed itself on many different fields. Even though the main factors remain, their importance share changes constantly. Main factor for this situation is the increase in development companies. Companies tend to realize more and more that development itself is the key factor that impacts the success or fiasco of the product. Based on the competition it would be unrealistically to expect customer loyalty in a case of bad experience with a certain product. Therefore it is necessary to target the key factors that have currently the biggest impact on the development. After that we can set the guidelines and activities to gain maximum output. Identification and optimising key factors can bring with relative small input significant outputs (Karakasic et al., 2016). As an example we can have a product that is by specification and usability very good but was 4 month delayed into the market. This brings consequences either way. It can mean company lost its market share, it can mean the sales are not as good as predicted or it could happen that the product doesn't sell at all. Either way there was a loss. On this occasion we didn't put brand reputation on the line or the global brand meaning into perspective in regards to delay.

Based on the before mentioned reasons it is absolutely crucial for the existing knowledge to be used as much as possible. Since there is a lot of knowledge present there is a need to put it in order and offer this knowledge to the developers. But to offer knowledge in a way that wouldn't consume a lot of time and thinking. For that reason a system that would help developers during different stages would be a very good option.

\section{Literature review}

Fields in which neural networks (NN) have been used are quite many. Also there are good enough data and examination being done in the field of product lifecycle. Also the optimisation approaches are shown. One of the optimisation approaches is being talked about in the paper that takes on optimisation of the costs during lifecycle 
with the hybrid method and the use of NN (Todic et al., 2017). When we talk about the product development it mostly means quite a vast and diverse fields which needs to be addressed. Therefore there are many fields that fit into the product development term. In the field of product manufacturing method FDM (fused deposition modelling) there was a method introduced which with the help of $\mathrm{NN}$ foresees the product manufacturing and helps to improve the end surface roughness (Vahabli \& Rahmati, 2016). Also it was developed a method that in regards to set processing parameters predicts the correlations of mechanical properties of the part (Vijayaraghavan et al., 2015) or predicts the cut quality of part edges (Klancnik et al., 2015). Similar method with the aim of improving the properties of the end product was also introduced in (Garg et al., 2014). On the topic of innovation in segment of production processes a method was introduced that upgraded the knowledge through innovation process (Wang et al., 2015). For the support on design oriented decisions there was a model introduced that is based on the Hebb's learning rule of NN. Therefore NN support is introduced even as early as in the design stage (Comesana-Campos \& BouzaRodriguez, 2016). For managing complexity during production, there was on the production model of dishwashers a model introduced for managing complexity of inventory and production which provides optimal decisions during phases of production (Wu et al., 2016). For helping companies during customer data collecting and adjustment to these needs there was a model introduced, which with the help of advanced techniques acquires the data and segments it for later usage. Therefore the company response time for adjustment is decreased. In the area of product optimisation (case study of shaft in high performance compressor) the process was introduced which evaluated different properties of the product with the help of NN. Therefore the developer was able to choose the appropriate solution based on the data and in the meantime also decrease the development time and costs (Liu et al., 2016). For the decision of the product itself, a model has been introduced, which combines functions of design, development and marketing as early as in the concept phase for the purpose of optimal end product. Study has been carried out on the case study of the iron (Kwong et al., 2016). In 2015 an article has been published in which optimisation process with the help of advanced methods has been introduced (Noorossana et al., 2015). Interesting work has been shown in the area of quality improvement. $\mathrm{NN}$ method has been introduced into existing Taguchi method. On the study case a $7.8 \%$ gain has been shown (Lin et al., 2015). In 2014 there was a NN model introduced for the purposes of predicting turbine blades (Duan et al., 2014). For the evolution of design a model has been developed which predicts adequacy in regards to potential customer response (Chen \& Chang, 2014). Similar model has also been investigated in (Tang et al., 2013). In the case study of solar panels an approach has been introduced which evaluates technical and nontechnical attributes during development for the optimal end product (Chen et al., 2013) and similarly for other products (Harih et al., 2015). Companies tend to use different requirements checklist to achieve different needs and demands. NN method was introduced also into QFD methodology (Kutschenreiter-Praszkiewicz, 2013). In the field of evaluation of mechanical properties where mostly numerical methods are being used there was a method based on NN introduced in 2015. Case study has been done on bending model of concrete rods reinforced with polymer (Taha 
Buchmeister, B. \& Palcic, I.: Product Development Using an Intelligent Supporting...

et al., 2015). When developing a new product we have to think about the environmental impact too (Majstorovic et al., 2015).

\section{Supporting system definition}

To define the supporting system, we first need to divide product or, in our case, beverage appliance in the smaller groups. Methodology that is often used here is to divide the appliance in sub-assemblies. In the recent times also dividing based on functionality and purpose is being done. For the development purposes the base dividing was being done with 6 sub-assemblies. Therefore those sub-assemblies are housing, user interface, carrying parts, vital parts, electronics and interactive parts (Fig. 1). In those 6 main areas parts and different assemblies are being placed. Also needed is the further sub-division in the area of each part. Therefore in the part level the system was divided into 7 categories. Those categories consist of function, operating field, type of load, classification (part/assembly), material, manufacturing process and type of bond. Because of the module concept the list can be expanded but for the development purposes the following concept is adequate.

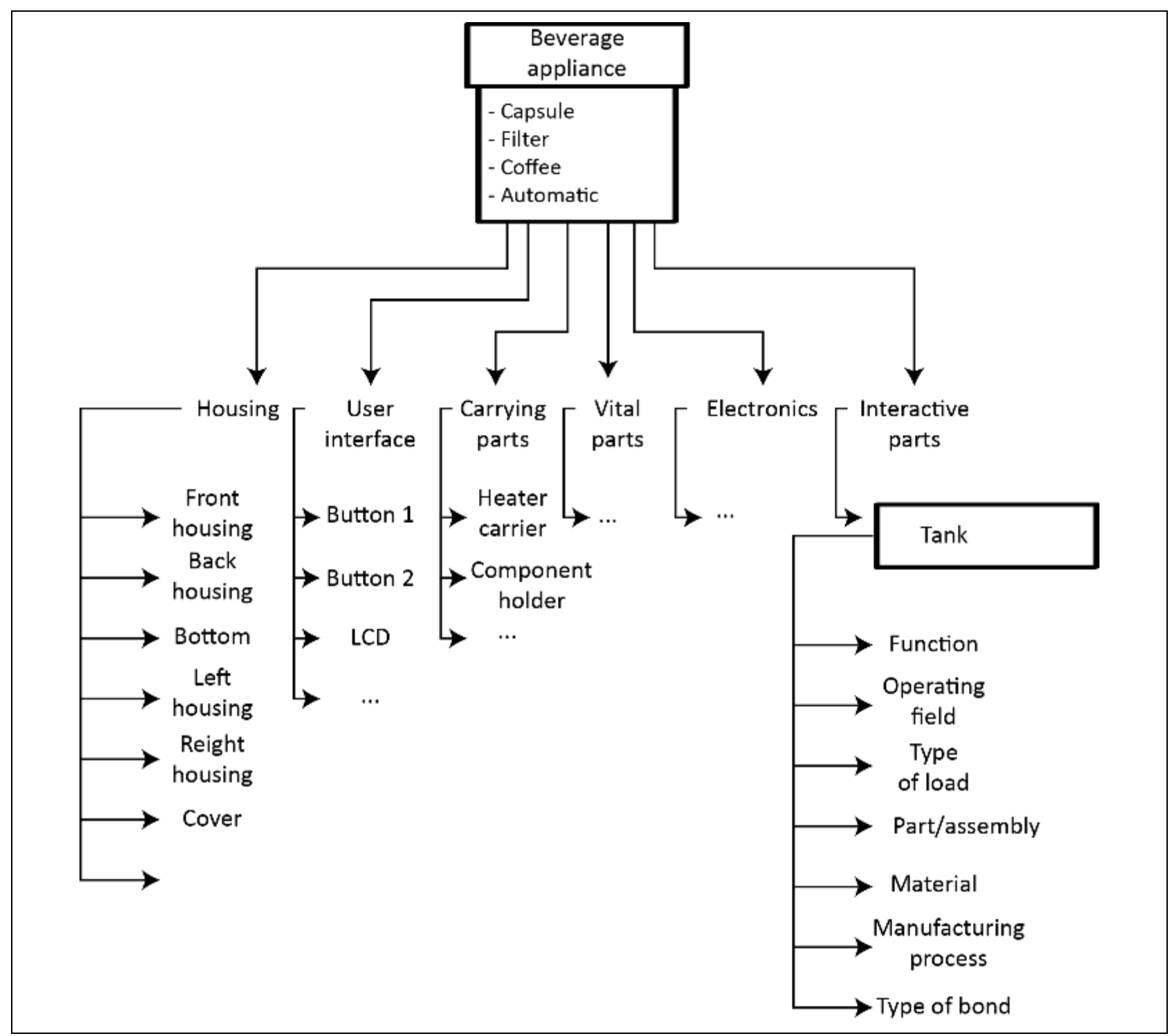

Fig. 1. Supporting system scheme. 


\section{Supporting system and neural modules}

\subsection{Methodology and framework}

To the basic supporting system NN modules were added to support the developers during different phases of the product development. Modules were developed with the methodology of neural networks and backpropagation learning algorithm. With the backpropagation learning method a learning sample is introduced into the neural network which later checks the output. Output sample is then introduced to the expected sample and based on the deviation an error is calculated. Weights are adjusted based on the error calculated. Algorithm adjusts the weights based on the $R M S$ error of the output sample. Samples are then over and over introduced into the network until the error is not sufficiently small. Schematic mathematical model of the neuron is shown in Fig. 2.

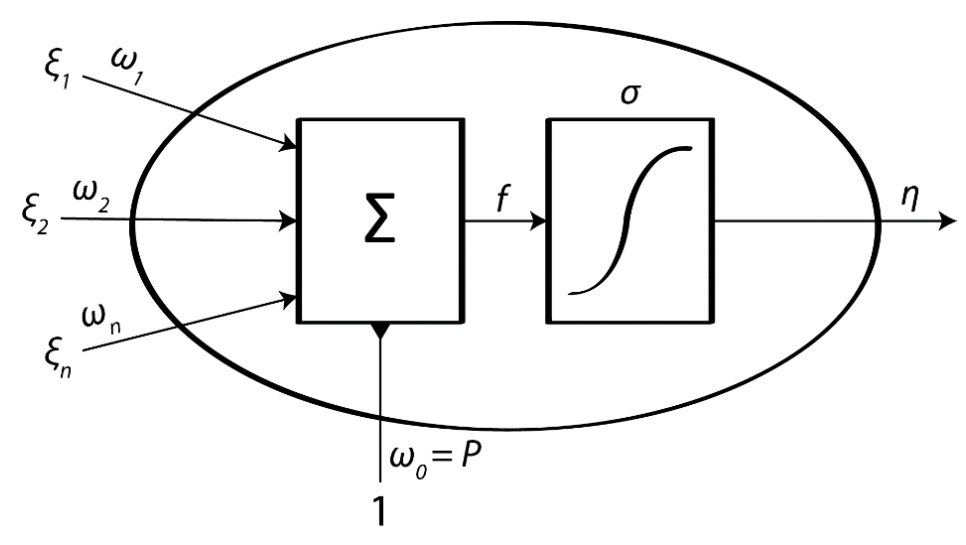

Fig. 2. Mathematical model of neuron.

Description of the variables in Fig. 2:

- $\eta$ - neuron output, based on output function,

- $\sigma$ - output function or activation function,

- $\xi_{j}$ - primary variables, which can contain digital or analogue values $(j=1, \ldots, n)$,

- $\omega_{j}-$ weights of input variables $(j=1, \ldots, n)$,

- $P$ - threshold value or threshold of element,

- $f$ - function.

Function of the model of the neuron can be described with the below shown equation:

$$
\eta=\sigma(f)=\sigma\left(\sum_{j=1}^{n} \omega_{j} \xi_{j}-P\right)
$$

There is more than one activation function available for activating the neuron in the model. Because of the usability of the function itself a sigmoid activation function has been chosen (Fig. 3). This function has whole range of continuous values from 0 to 1 available. 


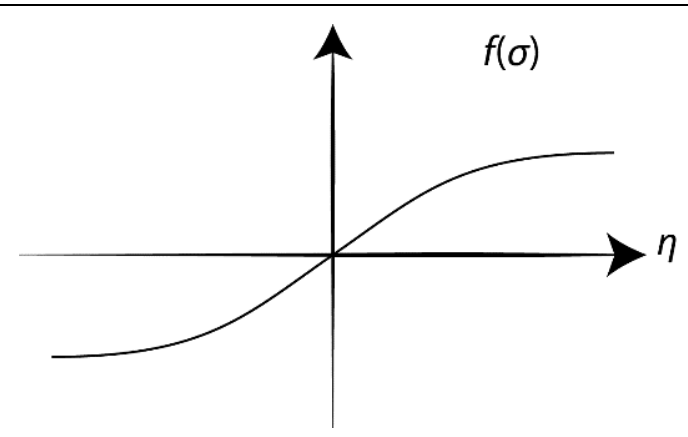

Fig. 3. Sigmoid activation function.

With the help of before fixed database of data from the selection of 24 appliances and other different databases there were implemented 7 modulus systems for helping during development. Systems were divided into 2 separate fields depends on the functionality. Under the quantitative NN systems, the systems for selection of material, production process and type of bond were placed. Those systems suggest a selection of possible solutions based on the desired parameters. Under the qualitative systems the systems for evaluating the appliance price, size of the injection machine, number of required of gate points and checking of adequacy of the snap fit are placed. This systems propose qualitative results for orientation during development. Schematic presentation of the system with implemented modules is shown in Fig. 4.

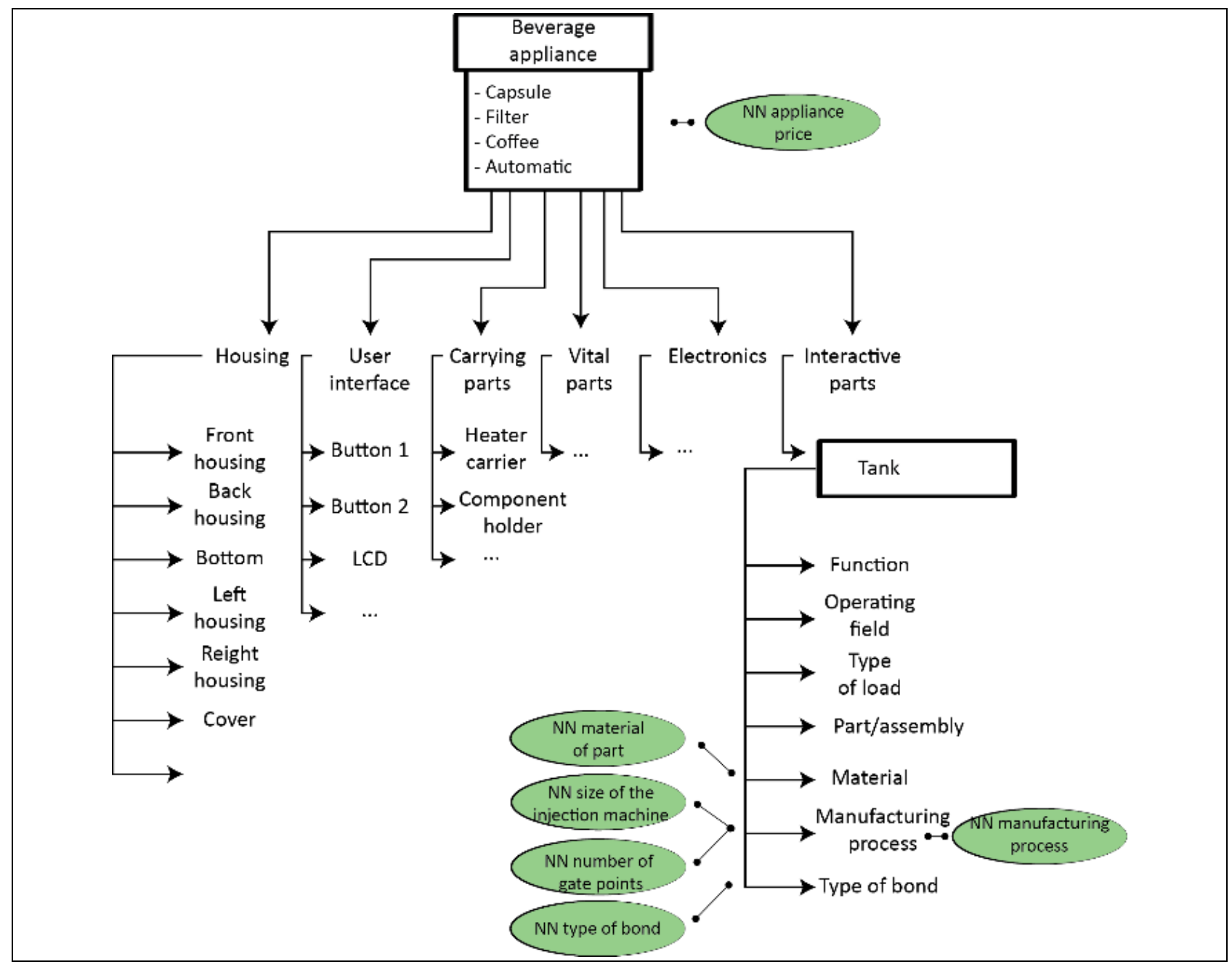

Fig. 4. Supporting system with implemented NN modules. 


\subsection{Creating NN modules}

Implementation and training of neural networks was done with the software framework Multiple backpropagation (MBP). This software framework allows easy and fast implementation of the network topology itself and learning. After the implementation it is possible to test the network with the patterns that were initially not introduced during training. So it is possible to evaluate the robustness in regards of usage. Support modules were executed with various configurations. Since each module's purpose is different also data about each NN varies. With that in mind Root Mean Square $(R M S)$ of one network can on paper be better but the network with bigger $R M S$ works better on real examples. Training of networks was taking place in series and endured till the networks fit the learning configuration at least $90 \%$. When this threshold was achieved the fine tuning process took place. This meant the aim to lower the $R M S$ value as much as possible. In practice this meant retraining the network over and over again from the acceptable configuration onwards. The following Table 1 shows the end configurations regarding the number of input data, hidden neurons, output data, needed iterations to achieve end network, $R M S$ of the network and the number of learning patterns.

\begin{tabular}{|l|c|c|c|c|c|c|}
\hline \multicolumn{1}{|c|}{ Module } & $\begin{array}{c}\text { Number } \\
\text { of inputs }\end{array}$ & $\begin{array}{c}\text { Number } \\
\text { of hidden } \\
\text { neurons }\end{array}$ & $\begin{array}{c}\text { Number } \\
\text { of outputs }\end{array}$ & Iterations & $\begin{array}{c}R M S \text { of } \\
\text { learning }\end{array}$ & $\begin{array}{c}\text { Number of } \\
\text { learning } \\
\text { patterns }\end{array}$ \\
\hline $\begin{array}{l}\text { Price of the } \\
\text { appliance }\end{array}$ & 28 & 42 & 1 & 45864 & 0.0017 & 24 \\
\hline Material & 24 & 86 & 43 & 468000 & 0.0606 & 43 \\
\hline $\begin{array}{l}\text { Manufacturing } \\
\text { process }\end{array}$ & 13 & 34 & 17 & 16665 & 0.125 & 17 \\
\hline Type of bond & 16 & 36 & 13 & 73528 & 0.043 & 13 \\
\hline $\begin{array}{l}\text { Injection } \\
\text { machine size }\end{array}$ & 12 & 24 & 1 & 98276 & 0.00389 & 25 \\
\hline $\begin{array}{l}\text { Number of } \\
\text { gate points }\end{array}$ & 13 & 26 & 2 & 75311 & 0.0099 & 25 \\
\hline $\begin{array}{l}\text { Adequacy of } \\
\text { snap fit }\end{array}$ & 15 & 28 & 3 & 4944 & 0.013 & 26 \\
\hline
\end{tabular}

Tab. 1. Neural network module configurations.

\section{Testing of the system}

Testing of the system was carried out on the patterns that were initially not presented to the network as the learning inputs for NN training. Therefore it was assured the independent testing of the system that showed actual response of the system in real practice. The difference in the types of modules lead to the differences between results in range of an error. But it has to be said that for evaluating the suitability of 
Buchmeister, B. \& Palcic, I.: Product Development Using an Intelligent Supporting...

NN not only $R M S$ needs to be evaluated but also the deviation of the results in regard to expected data.

\subsection{Price of the appliance}

In this module there was 6 previously unknown appliances presented to the system. Expected end result was approximate price of the appliance in regards to the input data. Following Table 2 shows the actual system outputs in regards to the expected ones.

\begin{tabular}{|c|c|c|}
\hline Sample & Expected price & Real price \\
\hline 1 & 135.33 & 140 \\
\hline 2 & 172.70 & 150 \\
\hline 3 & 566.39 & 550 \\
\hline 4 & 661.52 & 650 \\
\hline 5 & 586.41 & 750 \\
\hline 6 & 52.15 & 70 \\
\hline
\end{tabular}

Tab. 2. Results of the testing module Price of the appliance.

The biggest deviation of the module was $26 \%$. The average deviation was $12 \%$ based on expected results. This kind of results which is based upon input data that take into account basic specifications and visual appearance of the appliance is more than good. Module therefore efficiently predicts the price of the appliance from the input specification and gives adequate guidelines for further development and optimization of appliances.

\subsection{Material of the part}

Because this module is of quantitative nature the results are provided quantitatively. Therefore the task of the module is to provide adequate materials for needed application from the database of 43 basic materials with 24 input parameters. From the possible 301 possible expected materials which system should propose, the system itself proposed or wrongly proposed 3 materials. This in sum means an error of $1 \%$. The result itself is more than adequate since it brings good decision support during development work. With introduction of more learning patterns inside $\mathrm{NN}$ the result can be further improved.

\subsection{Manufacturing process}

This module is similarly to previous one quantitative. It operates with the choice of 17 basic possible manufacturing processes. With the help of 13 given input parameters it offers the list of possible suitable processes. From 68 possibilities the module should offer, it proposed or wrongly proposed 3 processes. This combined means an error of $4 \%$. Deviation is greater than in previous module but a $96 \%$ accuracy is still sufficient for approximate use. System is also possible to be improved under additionally presented learning patterns. 


\subsection{Type of bonding}

Also this module is quantitative. From the selection of 13 possible basic types of bonding with regards to 16 input parameters, the module proposes selection of types of bonding that should be suited for a given application. From 65 possibilities that the module should offer it proposed or wrongly proposed 2 types of bonding. This means the combined error of $3 \%$. Percentage of the error is adequate for the development purposes. With retraining and introducing new learning patterns the error can be reduced.

\subsection{Injection machine size}

Within this module the aim was to test 5 before unknown configurations. The goal of the system was to get the clamping force needed for the part to inject with regards to 12 input parameters. With the help of clamping force estimation it is therefore possible to select the required injection machine size (Table 3).

\begin{tabular}{|c|c|}
\hline Sample & Clamping force \\
\hline 1 & $23 \mathrm{kN}$ \\
\hline 2 & $30 \mathrm{kN}$ \\
\hline 3 & $187 \mathrm{kN}$ \\
\hline 4 & $89 \mathrm{kN}$ \\
\hline 5 & $305 \mathrm{kN}$ \\
\hline
\end{tabular}

Tab. 3. Results of the testing module Injection machine size.

The biggest deviation of the module was $39 \mathrm{kN}$. Average deviation was calculated at $25.8 \mathrm{kN}$ based on the expected results. The range of error is acceptable since the calculated errors don't affect choosing procedure too much as the size range of the machines is quite big.

\subsection{Number of gate points}

In this module there were 5 previously unknown configurations tested. The aim of the system was to determine the number of the needed gate points based on the information given by 13 input parameters (Table 4). With the help of this information it is later possible to choose the injection system and also determine the price of it.

\begin{tabular}{|c|c|}
\hline Sample & Number of gate points \\
\hline 1 & 1 \\
\hline 2 & 1 \\
\hline 3 & 1 \\
\hline 4 & 1 \\
\hline 5 & 1 \\
\hline
\end{tabular}

Tab. 4. Results of the testing module Number of gate points.

Here the system in regards to the test samples didn't deviate which means there was no error present. 
Buchmeister, B. \& Palcic, I.: Product Development Using an Intelligent Supporting...

\subsection{Adequacy of snap fit}

In this module 6 previously to the system unknown configurations were presented. Task of the system was to provide in regards to 15 input parameters the maximum force of deflection needed for snap fit, the maximum stress and to give recommendation about the suitability of the snap fit for the given application (Table 5).

\begin{tabular}{|c|c|c|c|}
\hline Sample & Force of push & Tensile stress & Suitability \\
\hline 1 & 112.70 & 242.8791 & 0.00 \\
\hline 2 & 22.52 & 30.59393 & 0.99 \\
\hline 3 & 18.066 & 30.2434 & 0.98 \\
\hline 4 & 130.85 & 184.3562 & 0.03 \\
\hline 5 & 31.35 & 78.30119 & 0.00 \\
\hline 6 & 49.52 & 110.2825 & 0.03 \\
\hline
\end{tabular}

Tab. 5. Results of the testing module Adequacy of snap fit.

The maximum bending force deviation here was $16.4 \mathrm{~N}$. Average deviation was $6.2 \mathrm{~N}$. Maximum deviation of tensile stress was $30.2 \mathrm{MPa}$. Average stress deviation was $12.7 \mathrm{MPa}$. System correctly predicted suitability of all the snap fit solutions that were in the test portfolio. There was no mistake. Based on the deviation of values shown the system itself is effective enough for prediction of snap fit adequacy. With retraining and presenting of new patterns during learning it is possible to further optimize the module.

\section{Conclusion}

Implementation of the supporting system that is based around neural networks is bringing significant improvements in the product design phase. Not only is the concept appealing in regards ease of use, it is also taking into account the existing knowledge. The concept itself uses the existing knowledge for its work, which is otherwise in most companies shared verbally or though other channels. The later concept almost never transfers the knowledge to the right place. The information mostly gets lost.

With the case study of supporting system it was shown that the system itself is efficient enough to provide solid information during different development phases. The biggest error provided by the module for estimation of appliance price was $24 \%$ in regards to expected price. Other modules were from the error perspective even more successful. With the constant knowledge database expansion it is possible to upgrade and improve the accuracy of the system constantly. Also because of the module assembly of the whole system it is possible at any time to easily swap or upgrade any certain module. Therefore, it is possible, in a case of demands increase in a certain area, the parameters in modules can be added or even output requests changed. This is also a logical future path as there are always new demands for new knowledge during development. Therefore a system grows and knowledge database is not getting lost but is constantly upgraded. With simple implementation we also avoid unreliable methods for knowledge transfer. Since the system itself is quick it also means we gain time 
during some phases which can then be allocated to different areas in need. A mention about quality increase is also in place as the system based on the previous knowledge warns about the potential mistakes at new products. We can conclude that the proposed system represents an effective way of development process optimization in the future. This could also mean more time in the future could be spent on the most challenging tasks, since the supporting systems could take over some other tasks.

\section{References}

Brglez, S. \& Dolsak, B. (2016). A necessity-based method for product requirement elicitation and classification. Transactions of FAMENA, Vol. 40, No. 1, pp. 87-110, ISSN 1333-1124

Chen, H. Q.; Honda, T. \& Yang, M. C. (2013). Approaches for identifying consumer preferences for the design of technology products: A case study of residential solar panels. Journal of Mechanical Design, Vol. 135, No. 6, Paper ID 061007, 12 pages, ISSN 1050-0472

Chen, H.-Y. \& Chang, Y.-M. (2014). Development of a computer aided product-form design tool based on numerical definition scheme and neural network. Journal of Advanced Mechanical Design Systems and Manufacturing, Vol. 8, No. 3, pp. 14-39, ISSN 1881-3054

Comesana-Campos, A. \& Bouza-Rodriguez, J. B. (2016). An application of Hebbian learning in the design process decision-making. Journal of Intelligent Manufacturing, Vol. 27, No. 3, pp. 487-506, ISSN 0956-5515

Duan, W.; Liqiang, A. \& Zhangqi, W. (2014). Strength reliability analysis of turbine blade using surrogate models. Research Journal of Applied Sciences, Engineering and Technology, Vol. 7, Paper ID 649046, pp. 3699-3708, ISSN 2040-7459

Garg, A.; Tai, K.; Lee, C. H. \& Savalani, M. M. (2014). A hybrid M5'-genetic programming approach for ensuring greater trustworthiness of prediction ability in modelling of FDM process. Journal of Intelligent Manufacturing, Vol. 25, No. 6, pp. 1349-1365, ISSN 0956-5515

Harih, G.; Borovinsek, M.; Ren, Z. \& Dolsak, B. (2015). Optimal products' handhandle interface parameter identification. International Journal of Simulation Modelling, Vol. 14, No. 3, pp. 404-415, ISSN 1726-4529

Karakasic, M.; Zadnik, Z.; Kljajin, M. \& Duhovnik, J. (2016). Matrix of function and functionality as a tool in product development process. Technical Gazette, Vol. 23, No. 5, pp. 1295-1300, ISSN 1330-3651

Klancnik, S.; Begic-Hajdarevic, D.; Paulic, M.; Ficko, M.; Cekic, A. \& Cohodar Husic, M. (2015). Prediction of laser cut quality for Tungsten alloy using the neural network method. Strojniski vestnik - Journal of Mechanical Engineering, Vol. 61, No. 12, pp. 714-720, ISSN 0039-2480

Koren, R. \& Palcic, I. (2015). The impact of technical and organisational innovation concepts on product characteristics. Advances in Production Engineering \& Management, Vol. 10, No. 1, pp. 27-39, ISSN 1854-6250

Kutschenreiter-Praszkiewicz, I. (2013). Application of neural network in QFD matrix. Journal of Intelligent Manufacturing, Vol. 24, No. 2, pp. 397-404, ISSN 0956-5515 
Kwong, C. K.; Jiang, H.-M. \& Luo, X.-G. (2016). AI-based methodology of integrating affective design, engineering, and marketing for defining design specifications of new products. Engineering Applications of Artificial Intelligence, Vol. 47, pp. 49-60, ISSN 0952-1976

Lin, M.-C.; Lin, Y.-H.; Lin, C.-C.; Chen, M.-S. \& Hung, Y.-C. (2015). An integrated neuro-genetic approach incorporating the Taguchi method for product design. Advanced Engineering Informatics, Vol. 29, No. 1, pp. 47-58, ISSN 1474-0346 Liu, J.; Yu, G.-Y.; Li, Y.; Wang, H.-M. \& Xiao, W.-S. (2016). Multidisciplinary design optimization of crankshaft structure based on cooptimization and Multi-Island genetic algorithm. Mathematical Problems in Engineering, Paper ID 9596089, 11 pages, ISSN 1024-123X

Majstorovic, V.; Medic, M. \& Bandic Glavas, M. (2015). Innovative PM approach to produce an environmentally friendly product, In: DAAAM International Scientific Book 2015, B. Katalinic (Ed.), pp. 423-430, DAAAM International, ISBN 978-3902734-05-1, ISSN 1726-9687, Vienna

Noorossana, R.; Zadbood, A.; Zandi, F. \& Noghondarian, K. (2015). An interactive artificial neural networks approach to multiresponse optimization. International Journal of Advanced Manufacturing Technology, Vol. 76, No. 5-8, pp. 765-777, ISSN 0268-3768

Taha, B. O.; Ali, P. J. M. \& Ahmed, H. A. (2015). Optimizing the flexural strength of beams reinforced with fiber reinforced polymer bars using back-propagation neural networks. ARO. The Scientific Journal of Koya University, Vol. 3, No. 2, pp. 1-10, ISSN 2410-9355

Tang, C. Y.; Fung, K. Y.; Lee, E. W. M.; Ho, G. T. S.; Siu, K. W. M. \& Mou, W. L. (2013). Product form design using customer perception evaluation by a combined superellipse fitting and ANN approach. Advanced Engineering Informatics, Vol. 27, No. 3, pp. 386-394, ISSN 1474-0346

Todic, V.; Cosic, I.; Maksimovic, R.; Tasic, N. \& Radakovic, N. (2017). Model for simulation of life cycle costs at the stage of product development. International Journal of Simulation Modelling, Vol. 16, No. 1, pp. 108-120, ISSN 1726-4529

Vahabli, E. \& Rahmati, S. (2016). Application of an RBF neural network for FDM parts' surface roughness prediction for enhancing surface quality. International Journal of Precision Engineering and Manufacturing, Vol. 17, No. 12, pp. 1589-1603, ISSN 2234-7593

Vijayaraghavan, V.; Garg, A.; Lam, J. S. L.; Panda, B. \& Mahapatra, S. S. (2015). Process characterisation of 3D-printed FDM components using improved evolutionary computational approach. International Journal of Advanced Manufacturing Technology, Vol. 78, No. 5-8, pp. 781-793, ISSN 0268-3768

Wang, G.-F.; Tian, X.-T.; Geng, J.-H. \& Guo, B.-A (2015). A knowledge accumulation approach based on bilayer social wiki network for computer-aided process innovation. International Journal of Production Research, Vol. 53, No. 8, pp. 2365-2382, ISSN 0020-7543

Wu, H.; Evans, G. \& Bae, K.-H. (2016). Production control in a complex production system using approximate dynamic programming. International Journal of Production Research, Vol. 54, No. 8, pp. 2419-2432, ISSN 0020-7543 